\title{
Carregadores de Açaí: Análise ergonômica do trabalho de carregadores de Açaí do Mercado Ver-o- Peso em Belém do Pará
}

\author{
Porters of the Açaí Berry: An ergonomic analysis of porters \\ labor of the açaí in the Ver-o-Peso Market in Belem, Para State
}

\author{
J oão Bosco de Assis Rocha* \\ Universidade Federal do Pará-UFPA, Belém, Pará, Brasil
}

Edmundo Rinolino Magalhães Flores**

Universidade Federal do Pará-UFPA, Belém, Pará, Brasil

Leandro Cavalcante Lima**

Universidade Federal do Pará-UFPA, Belém, Pará, Brasil

\section{Leandro de J esus Rodrigues**}

Universidade Federal do Pará-UFPA, Belém, Pará, Brasil

\begin{abstract}
RESUMO
A atividade de carregador de açaí é típica da Amazônia. Para investigar aspectos ergonômicos desta atividade foram aplicados a 30 trabalhadores, cerca de $10 \%$ dessa população em Belém, o Questionário Nórdico de Sintomas Osteomusculares - QNSO (PINHEIRO; TRÓCCOLI; CARVALHO, 2002), objetivando conhecer sintomas de inadequações laborais. O estudo teve caráter exploratório e descritivo. Adicionalmente, foi realizada análise profissiográfica para melhor compreensão da atividade e as suas inadequações. A idade dos entrevistados variou de 15 a 58 anos (média=27 anos), o tempo de serviço de um mês a 20 anos e a jornada diária de 3 a 14 horas. As maiores frequências de sintomas foram: dorsal superior, 56,6\%; dorsal inferior, $63,3 \%$, e membros inferiores, 53\%. Os resultados denunciaram a precariedade do trabalho ocasionada pela quantidade de peso transportada pelos trabalhadores, posição dos barcos, marés e condições meteorológicas. Este estudo pioneiro constatou a necessidade de implementação ergonômica.
\end{abstract}

Palavras-chave: carregadores de açaí, ergonomia, atividade portuária.

\begin{abstract}
Carrying loads of the Açai Berry is a common activity in the Amazon. In order to investigate ergonomic aspects of these activity, the Nordic Osteomuscular Symptom Questionnaire - NOSQ (PINHEIRO; TRÓCCOLI; CARVALHO, 2002) was administered to 30 workers, or about $10 \%$ of this work force in Belem. The purpose was to ascertain organic problems produced by substandard labor conditions. The study was exploratory and descriptive character. In addition, a professional profile analysis was
\end{abstract}


undertaken. Time spent in this activity varied from one month to 20 years, and on a daily basis consumed between three to 14 working hours. The highest frequency of maladaptive symptoms included the upper back $(56.1 \%)$, lower back (63.3\%), and the lower limbs (53\%). The professional profile furnished details concerning the effects of hauling baskets of Açaí under precarious labor conditions, such as the boat position, tidal and weather changes, as well as the amount of weight to be transported. This pioneering study noted the need for ergonomic implementation.

Keywords: açaí porters, ergonomics, longshoremen.

\section{I ntrodução}

Por sugestão da Fundação Jorge Duprat Figueiredo de Segurança e Medicina do Trabalho - FUNDACENTRO, Centro Estadual de Saúde de Belém, uma análise ergonômica do trabalho de carregadores de açaí foi realizada no Mercado Ver-o-Peso, em Belém, conforme descrita neste artigo. Este interesse da FUNDACENTRO deveu-se a solicitações oriundas de algumas entidades ligadas aos referidos trabalhadores, localizadas em Belém e tendo em vista queixas formuladas por eles, relacionadas às condições precárias de trabalho e às consequências danosas à saúde. A partir da análise ergonômica do trabalho dos carregadores de açaí foi possível, então, conhecer e avaliar detalhadamente essa atividade secular, porém ausente na literatura a respeito do assunto.

Segundo se proclama na Cidade e conforme afirma a Wikipédia (2010, página principal), o Ver-o-Peso “é a maior feira livre da América Latina", assertiva que carece de informações e comprovações que possam de fato conferir o título ao Mercado. Por outro lado, pode-se dizer com segurança que este cartão postal de Belém é formidável em termos de aglomeração humana, bem como de mercadorias extrativistas, na sua maioria, oriundas do Estado do Pará e da Amazônia. Contam os historiadores que o Mercado é tão antigo quanto a cidade, pois foi naquela região, no Século XXVII, que tudo começou. Ali há um intenso movimento de embarcações carregadas de paneiros ou rasas, uma espécie de cesto, que começa no verão por volta das 19 horas e no inverno em torno das quatro da madrugada, terminando mais ou menos às 7 ou 10 horas da manhã, dependendo da época do ano. Inverno, na linguagem nortista, significa tempo de chuva, aliás, de muita chuva, o que acrescenta ainda mais precariedade às condições de trabalho daquelas pessoas que ali labutam. Supõe-se que a rotina rudimentar de trabalho dos trabalhadores daquele local seja realizada desde a fundação de Belém, em 1616, ou até antes desta data. No inverno ou no verão, na maré baixa ou alta, buscam a mercadoria nos barcos, colocandona em terra firme nas mãos dos comerciantes e atravessadores, sem qualquer facilitação ergonômica, em pleno século XXI, repleto de 
recursos tecnológicos. Falar em tecnologia, em facilitação, em ergonomia ou em mudança de condições de trabalho, pode sugerir a ideólogos extremados de plantão ameaças ao trabalhador, ao seu trabalho e à sua sobrevivência. Entretanto, tentativas para minimizar precárias e desumanas condições de trabalho dessas pessoas devem sobrepor a quaisquer ideologias. Se por um lado há essa preocupação por parte de alguns, parece haver descaso quanto às reais e básicas necessidades em relação às condições de trabalho dos carregadores portuários de açaí.

\section{Revisão da Literatura}

O conceito de higiene e segurança é um dos mais utilizados e fundamentais no mundo contemporâneo do trabalho, segundo os modos de prática laboral. Estudos nessa área são de grande importância para o desenvolvimento de tecnologias, auxiliando tanto empresas quanto trabalhadores. Eggers e Goebel (2007) consideram importantes os estudos investigativos, pois fornecem base para 0 conhecimento e servem de apoio para novas pesquisas e estudos, além de comparações com a realidade das organizações. A higiene e a segurança no trabalho contribuem significativamente para garantir a harmonia entre o oferecido pelo trabalhador e aquilo que ele realmente pode oferecer, sendo desejável que ambos os índices se mostrem equivalentes, tanto para benefício da organização quanto para o trabalhador. Santana, Santos e Rodrigues (2004) assinalam que atualmente saúde e segurança são imprescindíveis para a manutenção de um ambiente de trabalho saudável e produtivo, porque a observância de tais questões representa valorização do elemento humano como sendo essencial para o sucesso de qualquer organização. Higiene e segurança do trabalho são regidas por um conjunto de leis, normas, procedimentos técnicos e educacionais com a intenção de proporcionar integridade física e mental do trabalhador, preservando-o dos riscos à saúde, inerentes as tarefas do cargo e ao ambiente onde são executadas. (EGGERS; GOEBEL, 2007).

Nunca é demais ressaltar a importância para o avanço das técnicas utilizadas no trabalho, assim como o bem-estar nesses locais, criando garantias que evitem acidentes e doenças no trabalho. Essa preocupação do empregador com o trabalhador melhora o seu desempenho, o que resulta na melhoria do produto e serviços oferecidos. A prevenção dos acidentes através de um programa de higiene e segurança na empresa tende a reduzir os riscos de acidentes, perda de tempo e dinheiro para ambas as partes, empregado e empregador, colaborando para um bom relacionamento entre todos (EGGERS; GOEBEL, 2007). A realidade vista em muitas organizações nos revela que ainda estamos distantes de alcançar 
níveis tão elevados de segurança no trabalho e que estudos, como os existentes hoje, somente garantam a permanência em tais índices. $O$ que ainda se mostra evidente é a necessidade de melhorias constantes nessa área, e uma retrospectiva que indique os passos já dados pode servir de base motivadora para continuarmos impulsionando tais avanços.

Rodrigues et al. (2002) argumentam que a despeito do incremento do estudo a respeito das relações de trabalho e saúde, este não é um tema bem resolvido, merecendo mais atenção por parte dos envolvidos na questão. Mas, os autores consideram que tem havido esforços no sentido de haver diminuição de acidentes de trabalho e suas consequências. Em 2007, foram registrados 653.090 acidentes e doenças do trabalho, entre os trabalhadores assegurados da Previdência Social. Entre esses registros contabilizaram-se 20.786 doenças relacionadas ao trabalho. (MINISTÉRIO DO TRABALHO, 2008).

Uma das áreas do conhecimento que desperta mais atenção nos dias atuais, em se tratando de higiene e segurança ocupacional, é a ergonomia. Isso se deve ao fato das importantes contribuições que estudos dessa natureza vêm dando, já há algum tempo, à área do trabalho. É indiscutível a importância da Ergonomia diante das ciências mais tradicionais, pois seus resultados são considerados, cada vez mais, confiáveis e significativos, principalmente diante do modelo de vida e trabalho adotado pela sociedade na contemporaneidade. Devemos considerar também que o labor é - se não a mais - uma das mais importantes atividades do homem e, caso não seja praticado, ele tende, na maioria das vezes, a ser situado à margem da sociedade. Todos são convocados para exercer suas atividades, sejam temporárias ou permanentes, diurnas ou noturnas, mais ou menos remuneradas, em uma mesa de escritório, em um equipamento numa fábrica, ou em viagens constantes, etc. Nesse aspecto a Ergonomia pode atuar como mediador para que a harmonia dessa relação homem $x$ trabalho se constitua e se mantenha.

Para Alencar Filho (1993) o vocábulo ergonomia foi criado pelo inglês K. F. Hywel Murrel, todavia, essa expressão já havia sido usada em 1857, em uma publicação intitulada Ensaios de Ergonomia ou Ciência do Trabalho, baseada nas leis objetivas da ciência sobre a natureza. A palavra Ergonomia vem do grego ergon, que significa trabalho, e nomos, que significa lei natural. A etimologia da palavra já indica o objetivo desta ciência e a sua relevância para o homem.

Para alguns autores a ergonomia é algo sem muita importância, significando apenas movimentação de cargas, mesas e assentos de trabalho, bem como questões relacionadas a peso e alturas (SANTOS; FIALHO, 1997). No entanto, para a maioria dos estudiosos e interessados na área, ela é mais complexa, podendo-se dizer que é uma tecnologia de comunicação e de interação entre homem e 
máquina, com o objetivo de proporcionar conhecimento sobre o assunto (MONTMOLLIN, 1971; LEPLAT, 1980). De natureza interdisciplinar, compreende diversas áreas profissionais, (GRANDJ EAN, 1998). Wisner (1987) diz que a ergonomia é um corpo de conhecimentos científicos relativos ao homem e indispensável para a concepção de ferramentas, máquinas e equipamentos para que possam ser utilizados com o máximo de conforto, segurança e eficácia. Finalmente, para Murrel (1965), pode ser definida como o estudo científico das relações entre o homem e o seu ambiente de trabalho. Segundo lida (1993), o surgimento da ergonomia teria ocorrido logo após a II Guerra Mundial, como consequência do trabalho interdisciplinar de profissionais como engenheiros, psicólogos e outros. No início a sua aplicação ocorria quase que somente na indústria e na relação homem-máquina. Hoje a ergonomia é mais abrangente, não se restringindo apenas a estes dois fatores, sendo aplicada nos vários tipos de atividades humanas. Este autor define ergonomia como "o estudo da adaptação do trabalho ao homem", mas argumenta:

O trabalho aqui tem uma acepção bastante ampla, abrangendo não apenas aquelas máquinas e equipamentos utilizados para transformar os materiais, mas também toda a situação em que ocorre o relacionamento entre o homem e o seu trabalho. Isso envolve não somente o ambiente físico, mas também os aspectos organizacionais de como esse trabalho é programado e controlado para produzir os resultados desejados. (IIDA, 1993, p.1).

Finalmente, Dul e Weerdmeester (1995, p. 13), sem definir ergonomia, argumentam que "se aplica ao projeto de máquinas, equipamentos, sistemas e tarefas, com o objetivo de melhorar a segurança, saúde, conforto e eficiência no trabalho". Explicam os autores que o termo ergonomia deriva do grego ergon (trabalho) e nomos (regras).

Com isso, podemos concluir que a ergonomia implica sempre e necessariamente no estudo do trabalho, exigindo observações das execuções de tarefas do trabalho in loco, com os devidos equipamentos e pessoas envolvidas durante a coleta e análise dos dados. É essencialmente uma ciência experimental e a sua prática, assim como qualquer outra, pressupõe um método para a sua elaboração.

Consideramos importante descrever brevemente a fase extrativista do açaí, para mostrar como essa cadeia extração - transporte comercialização permanece em um estágio tal que conserva os hábitos praticados ao longo de alguns séculos, tal como acontece no Mercado Ver-o-Peso, palco do trabalho descrito no presente artigo. 
Uma análise ergonômica dos apanhadores de açaí na Amazônia foi desenvolvida por Canto (2001). O autor analisou os aspectos posturais dos trabalhadores extrativistas do açaí na fase de coleta de fruto, por meio de testes e protocolos de posturas. Verificou que poucos apresentavam distúrbios músculos-esqueléticos graves, tendo apenas obtido relatos de frequentes quedas do apanhador de frutos da palmeira, devido ao seu peso, além de dores brandas nos pés, peito e costas. Diz o autor haver uma atenuação das consequências nocivas à saúde do trabalhador em função de empregarem estratégias desenvolvidas pela experiência e pela sabedoria popular, que é o conhecimento não-científico transmitido de geração a geração pelos habitantes da área.

O açaizeiro (Euterpe oleracea) é uma palmeira típica da região amazônica e o Estado do Pará é o principal centro de dispersão natural dessa palmácea. No estuário do Rio Amazonas se encontram as maiores e mais densas áreas dessa palmeira, adaptada às condições elevadas de temperatura, precipitação pluviométrica e umidade relativa do ar. A produção de frutos, que provinha quase que exclusivamente do extrativismo, a partir da década de 1990, passou a ser obtida, também, de açaizais nativos manejados e de cultivos implantados em áreas de várzea e de terra firme, localizadas em regiões com maior precipitação pluviométrica (HOMMA; NOGUEIRA; MENEZES; CARVALHO; NICOLE; MATOS, 2006).

A ampliação do mercado consumidor da polpa do açaí, além das fronteiras amazônicas, tem implicado em fortes transformações na dinâmica de produção local. Como destacam Homma et al. (2006), esta expansão está promovendo o aumento das áreas de manejo nas várzeas amazônicas e, com isso, está havendo uma grande transformação do beneficiamento tradicional por modernas indústrias, gerando exclusão social dos consumidores de menor poder aquisitivo e a introdução de novos sistemas de plantio e coleta do fruto, visando aumentar a produtividade da mão-de-obra e da terra.

Uma das principais rotas de comércio do açaí paraense passa pelo Mercado Ver-o-Peso, onde o progresso e a tecnologia em nada contribuíram durante séculos para a qualidade de vida dos carregadores do fruto, os quais são responsáveis em parte pela sua movimentação. Neste, sentido este estudo busca descrever as atividades desses carregadores portuários e levantar os principais sintomas físicos relacionados ao seu trabalho.

Enfim, por esta breve revisão da literatura concluímos ter havido evolução do conceito ergonomia, restrito ao estudo da relação homem-máquina inicialmente, tornando-se posteriormente mais abrangente. Daí a necessidade da busca do entendimento mais global das atividades exercidas pelos carregadores de açaí, sua organização, dificuldades, etc., ao se elaborar um estudo como este aqui apresentado. 


\section{Objetivo}

Geral: Analisar o trabalho do carregador de açaí do Mercado Ver-oPeso, objetivando compreender a sua organização, os instrumentos e os meios para desenvolvê-lo.

Específico: Analisar o trabalho sob o ponto de vista ergonômico.

\section{Método}

\subsection{Amostra}

Este estudo teve caráter exploratório e descritivo, sendo entrevistados os carregadores encontrados em meio à população geral do Mercado e/ou que se apresentavam para participar. Este critério foi utilizado tendo em vista a complexidade do local e as características de informalidade do grupo pesquisado.

Constituída de 30 homens, na faixa etária de 15 a 58 anos, a amostra estratificada, de caráter não aleatório, representa a população estimada de 300 trabalhadores informais e sem quaisquer vínculos com entidades classistas ou patronais, que atuam no Mercado Ver-oPeso. Em outros termos, são trabalhadores que convivem de forma tácita entre si e em relação aos demais frequentadores daquele ambiente, constituídos dos comerciantes e proprietários dos barcos que transportam o açaí até aquele local.

\subsection{Instrumentos e Técnicas}

\subsubsection{Observação in loco e registro em vídeo}

Foram realizadas cinco visitas ao Mercado Ver-o-Peso, com a finalidade de obtenção de conhecimento sobre as atividades dos carregadores de açaí. Em uma das visitas foi realizada a gravação em vídeo das situações de trabalho destinada a subsidiar a elaboração da análise profissiográfica, instrumento utilizado para descrever as atividades dos carregadores.

As análises profissiográficas, segundo o INPS (1969, Prefácio), "visam a relacionar com maior segurança a capacidade laborativa apurada com as exigências da atividade profissional". Sob o ponto de vista de Camacho (1984, p. 19), o termo "análise de tarefa" poderia ter sido empregado ao invés de análise profissiográfica, pois significa descrever "a ação ou um conjunto de ações que levam a um resultado imediato passível de avaliação". Rothmann e Cooper (2009, 
p.147) se referem à "descrição do cargo por escrito do que o trabalho envolve", ressaltando não haver um formato-padrão para a sua elaboração. Preferimos utilizar a primeira expressão, adotada pelo INPS, para designar a análise ou a descrição das atividades do carregador de açaí. O vídeo serviu para auxiliar na observação, captando os detalhes das suas ações e facilitando a sua descrição, conforme mostra a Figura 1.

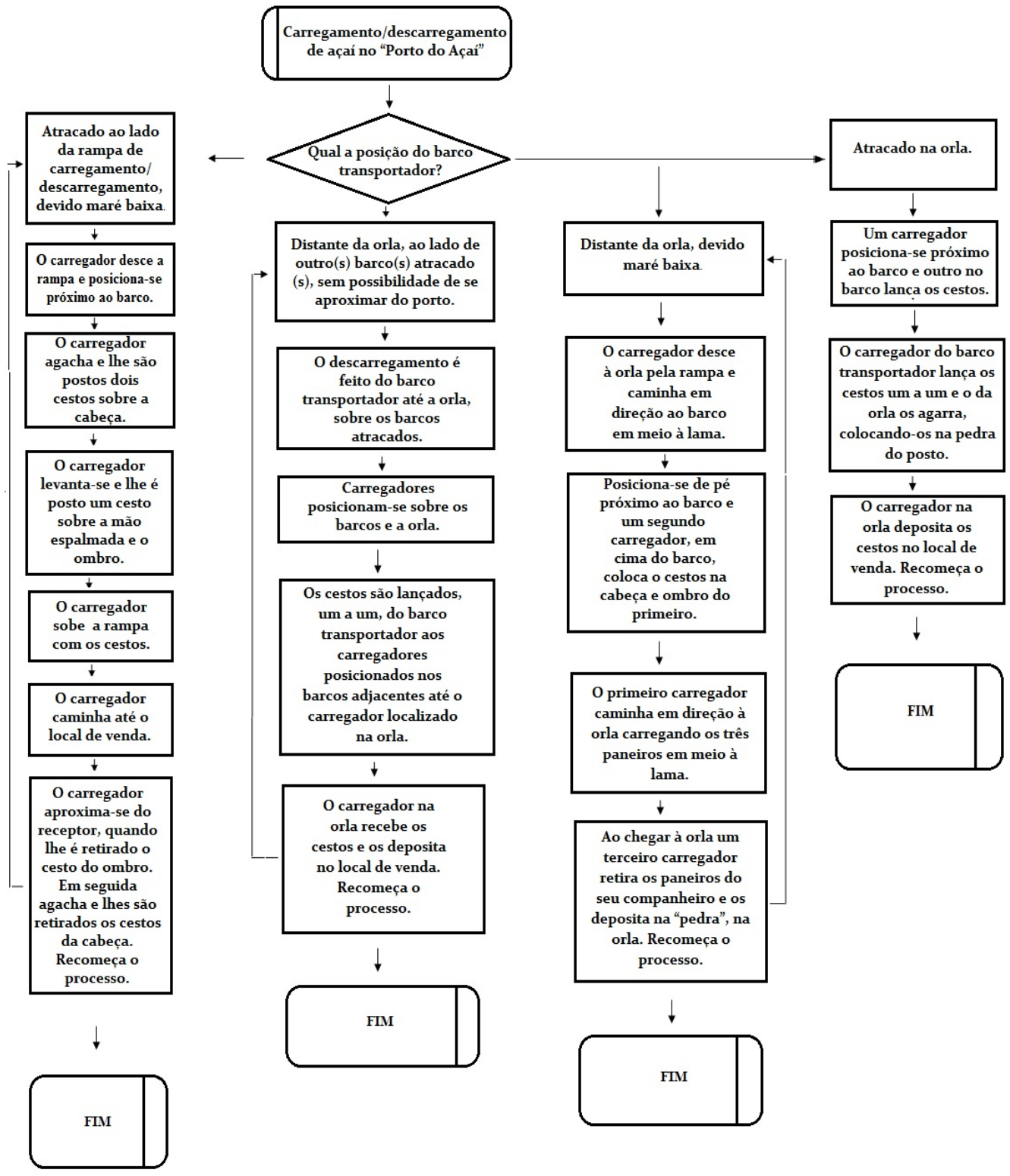

Figura 1. Análise profissiográfica das atividades dos carregadores. 


\subsection{Procedimentos}

\subsubsection{A entrevista}

A entrevista utilizada foi do tipo estruturada, constituída das perguntas contidas no QNSO, (Questionário Nórdico de Sintomas Osteomusculares) versão reduzida e validada por Pinheiro, Tróccoli e Carvalho (2002), bem como de outras relativas ao trabalho, família, lazer, qualidade de vida, etc. Uma seção foi incluída no instrumento para permitir a identificação dos dados sociodemográficos.

\subsubsection{Procedimentos}

Os respondentes eram convidados a assinalar em uma escala variável de 1 a 4 pontos, sendo $1=$ não; $2=$ raramente; $3=$ com frequência e $4=$ sempre, a frequência com que tinham sentido dor ou desconforto nos últimos 12 meses e nos últimos 7 dias, em nove regiões anatômicas (pescoço, ombros, braços, cotovelos, antebraços, punhos/mãos/dedos, dorso, região lombar e extremidades inferiores), tendo como referência uma figura humana (Figura 2, página 442).

Foram realizadas cinco visitas ao Mercado Ver-o-Peso, com os objetivos seguintes:

1. Visita: Conhecer, observar e registrar, em geral, as principais características da atividade de carregamento das rasas de açaí do barco aos pontos de venda no Mercado Ver-o-Peso. A partir desta observação a análise profissiográfica da atividade de carregador foi iniciada.

2a. Visita: Gravar em vídeo as fases de carregamento do açaí.

3a Visita: Continuar e aprofundar a análise profissiográfica por meio de observação in loco das atividades. No local foi entrevistado inicialmente um carregador o qual forneceu informações gerais sobre seu trabalho.

4a. Visita: Verificar a coerência entre a descrição feita na análise profissiográfica e o relato dos carregadores. A descrição realizada pelo grupo de estudo foi submetida a alguns carregadores para que participassem da construção e da avaliação do trabalho realizado pela nossa equipe.

5a Visita: Aplicar o Questionário Nórdico de Sintomas Osteomusculares - QNSO.

Três visitas ( $1^{\underline{a}}$, 4a e $5^{\underline{a}}$ ) foram realizadas entre 19:00h e 21:30h, quando os carregadores chegam ao porto e se concentram no local até que os barcos atraquem para que o trabalho de descarregamento do açaí seja efetuado. Duas visitas ( $2 \underline{a}$ e $4 \underline{a}$ ) foram realizadas às cinco e seis horas da manhã, respectivamente, ainda antes do sol nascer, permanecendo a equipe até sete ou oito horas, quando os 
carregadores executam o transporte do açaí para os veículos estacionados próximo da Feira.

Inicialmente, abordamos alguns carregadores para conversas informais. Um destes trabalhadores se colocou à disposição dos pesquisadores, servindo como mediador entre pesquisadores e carregadores, o que facilitou o contato com a população em estudo. Como medida ética, explicamos aos entrevistados os objetivos da pesquisa e a preservação das suas identidades.

\section{Resultados e discussão}

\subsection{Os dados sócio- demográficos}

A maior parte dos componentes deste aglomerado humano é composta pelos carregadores de açaí, estimada pelos seus participantes em torno de 300 homens, muitos dos quais iniciaram sua vida naquele local de trabalho quando ainda com 13, 14, 15 anos de idade, muitos dos quais substituindo seus pais ou trabalhando ao seu lado. Os paneiros e os sacos (mais raros) são descarregados desde as embarcações, que podem estar atracadas à margem do cais, quando a maré é alta; no início de uma rampa de acesso ao cais ou mais distante deste, quando à preamar. Em certas horas da noite ou madrugada, quando o movimento de barcos que chegam ao porto é intenso, muitos só conseguem atracar ao lado de outros já atracados, fazendo com que os paneiros ou sacos sejam jogados uma-um, de barco em barco, até a pedra, como dizem. Este procedimento é realizado exclusivamente com o esforço físico do carregador, pois não existe qualquer equipamento que facilite o seu trabalho. Cada paneiro pesa em torno de 13 quilos e em cada viagem, na maioria das vezes, o carregador empilha dois volumes na cabeça e um no ombro. Os sacos têm pesos equivalentes a essa carga transportada em forma de paneiros. Na maré baixa, quando os barcos se distanciam da margem, o esforço é maior, pois o carregador é obrigado a caminhar em meio à lama e ao lixo existente na orla, além de subir a rampa de acesso ao Porto.

A média de idade dos participantes encontrada foi de 27 anos, situada dentro de uma faixa etária de 15 a 58 . Os pesos dos participantes oscilaram entre 51 e 110, com uma média de $71,87 \mathrm{~kg}$. Vinte e três carregadores afirmaram ter uma união estável com suas companheiras, enquanto sete afirmaram não ter relação conjugal estável, ou se declaravam solteiros. A escolaridade encontrada foi a seguinte: ensino fundamental incompleto: 22; fundamental completo: 01; médio incompleto: 03 e médio completo 03. Um participante não opinou a respeito. 
Atividade de carregador é para a maioria a sua principal fonte de renda. Dentre os carregadores entrevistados apenas sete, $20 \%$, afirmaram ter outra ocupação além desta, relacionada ao processamento do fruto para fins de sua comercialização e consumo. O trabalho de carregador é informal, sendo que os "contratantes" dos serviços são os vendedores do açaí, fornecedores dos comerciantes varejistas, mais conhecidos como "marreteiros". No Mercado Ver-oPeso o trabalhador em geral precisa formar vínculos com outros carregadores que o convidaram ou o aceitaram para ajudar no trabalho, dividindo os lucros e vínculos com o marreteiro.

Conforme um carregador entrevistado comenta:

O Ver-o-Peso não tem dono. A pessoa tem que ter papo. Se entrosar com alguém, vai fazendo amizade, até ter amizade com todos. Daí alguém pode te chamar para ajudar em um carreto. Se for um cara bom de serviço o marreteiro te chama. (C., 15 de Junho de 2009).

Observamos, também, muitas crianças catando os frutos espalhados pelo piso de paralelepípedos do Mercado, o que, de certa forma, parece caracterizar os primeiros passos dos meninos na atividade de carregador. É a perpetuação de uma prática rudimentar secular.

O tempo de trabalho dos entrevistados variou de 1 mês a 20 anos de serviço no Mercado Ver-o-Peso, sendo a média de 10 anos. A atividade dos carregadores é exercida nos horários da noite, madrugada e manhã. Por volta das $19 \mathrm{~h}$ os carregadores aos poucos chegam ao Mercado para aguardar a chegada dos barcos para realizarem o descarregamento e, enquanto não há trabalho, se reúnem em grupos para conversar ou realizar alguma atividade de lazer, como jogar baralho. A jornada de trabalho segue pela madrugada e só termina por volta das $7 \mathrm{~h}$ ou $10 \mathrm{~h}$ da manhã, dependendo do período de safra do açaí, que varia de acordo com as estações chuvosas ou não, conforme já mencionado. Entre os entrevistados a jornada de trabalho diária oscilou de 3 a 14 horas de serviço, sendo a média de 12 horas. Para descanso são reservadas em média 5 horas, despendidas dormindo, na sua maioria. Como lazer os participantes relataram como principal atividade "jogar bola" $(40 \%)$ e de forma pouco expressiva apareceram atividades como "sair para passear", "beber cerveja", "ir à praia", "brincar com filhos", "jogar bilhar, "jogar vídeo-game" ou não indicaram atividade de lazer. 


\subsection{Os sintomas osteomusculares}

Os 30 carregadores que responderam o Questionário Nórdico de Sintomas Osteomusculares - QNSO (versão reduzida e validada por PINHEIRO; TRÓCCOLI; CARVALHO, 2002), indicaram as principais regiões em que apresentaram, nos últimos 12 meses e nos últimos sete dias, sintomas tais como dores, parestesias (dormência, formigamento, diminuição da sensibilidade), sensação de peso e/ou fadiga. Na Figura 2, o esquema indica as principais regiões do corpo em que os carregadores são acometidos.

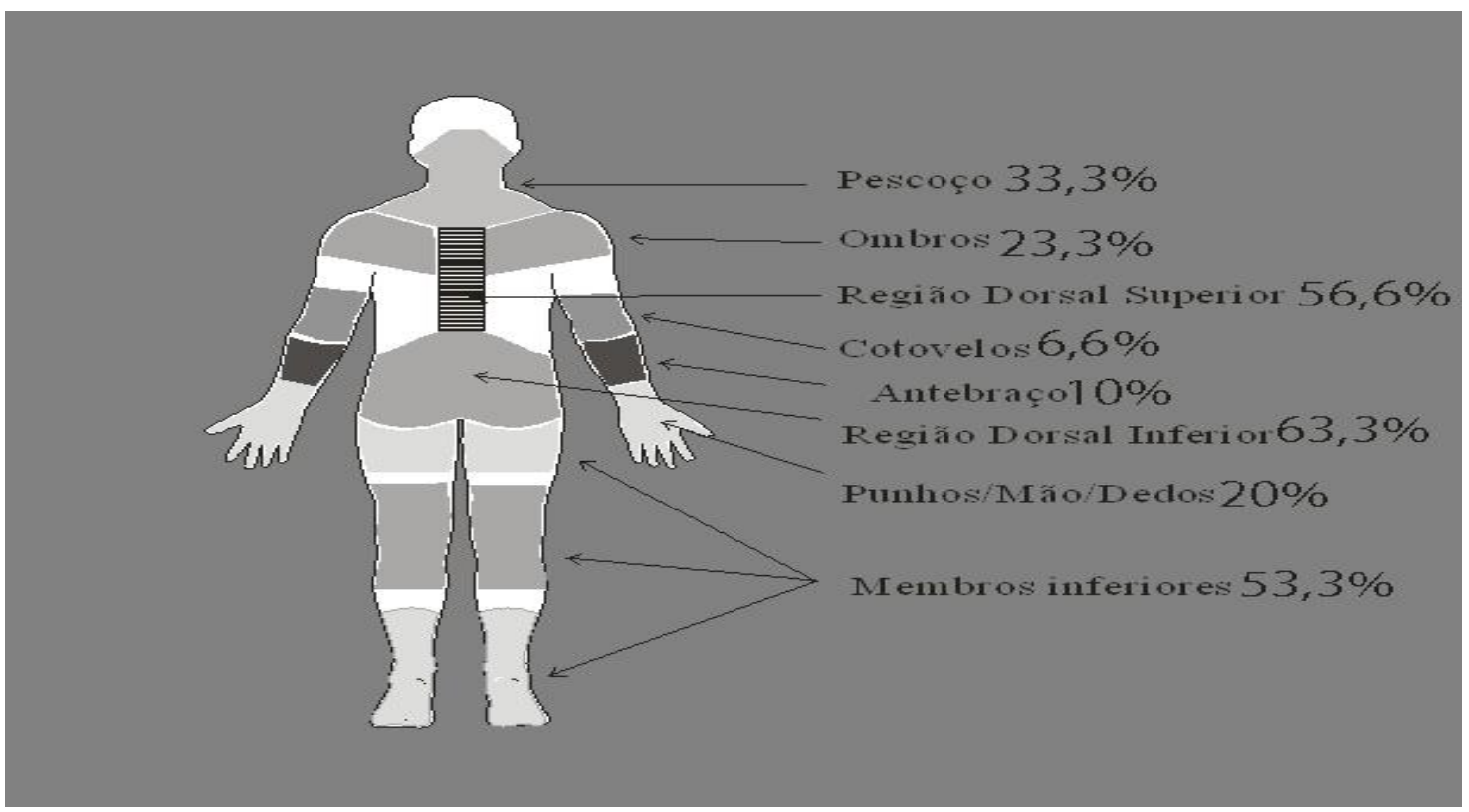

Figura 2. Esquema das regiões do corpo humano avaliadas.

Apenas 6,6\% dos entrevistados disseram não sentir dor em qualquer parte do corpo. Devemos ressaltar em primeiro lugar que este foi possivelmente uma das primeiras - se não a primeira - incursão no Mercado Ver-o-Peso, com intenções ergonômicas, realizada com os carregadores daquele local. Devemos admitir também que foi apenas o início de um trabalho que necessita maior aprofundamento por profissionais das diversas áreas do conhecimento, tais como saúde, ciências sociais, administração, ergonomia, previdência social, serviço social, etc.

A análise profissiográfica dos carregadores (Figura 1), confrontada com os resultados encontrados, referentes às dores mencionadas e localizadas nas diversas partes do corpo desses trabalhadores, mostram indícios de inadequação de condições de trabalho, os quais podem causar danos à sua saúde. O trabalho essencialmente braçal utilizado nestas atividades analisadas é rudimentar e praticado há mais de quatro séculos sem as mínimas condições laborais oferecidas a um trabalhador. Não há, portanto, qualquer facilitação mecânico- 
instrumental, como guindastes, carregadeiras e outros equipamentos para que esta atividade seja realizada com mais conforto, eficiência e segurança e, consequentemente, com menos desgaste físico. De certa forma, estas condições de trabalho mais modernas já existem no Porto de Belém, situado a apenas algumas centenas de metros do Mercado Ver-o-Peso, bem como em outros portos do Brasil.

Diversas medidas poderão ser tomadas a fim de proporcionar melhorias na atividade de carregamento do açaí, a partir dos dados obtidos nesse trabalho, mas, preferencialmente, faz-se necessária uma melhor avaliação sobre outros fatores que antecedem e são responsáveis por esse status do carregador do Mercado Ver-o-Peso.

\section{Conclusões}

Talvez uma das constatações importantes obtidas durante a realização deste estudo foi a de que os carregadores de açaí não possuem qualquer organização social e parecem trabalhar tal qual imaginamos como o faziam no início, ou até antes da fundação de Belém. Concluímos também que se dentro desta realidade, em torno da atividade, não houve um mínimo de organização social, parece não ter ocorrido ao longo do tempo qualquer evolução que pudesse ter melhorado ou facilitado a relação do trabalhador com a sua atividade, minorando o seu esforço físico e proporcionando mais ganhos por mercadoria transportada.

Os resultados deste estudo não são conclusivos, mas pretendem ser uma contribuição para que a atividade em foco seja organizada e os trabalhadores possam conviver melhor com o seu trabalho. O QNSO (PINHEIRO; TRÓCCOLI; CARVALHO, 2002) revelou esforços físicos acentuados em determinadas partes do corpo dos carregadores, um sintoma que parece denunciar inadequação laboral de alguma forma, como falta de equipamentos, condições inadequadas, mostrada pela análise profissiográfica, construída a partir de vídeos, relatos e observações in loco. Relembrando lida (1993, p. 1), ergonomia "envolve não somente o ambiente físico, mas também os aspectos organizacionais de como esse trabalho é programado e controlado para produzir os resultados desejados".

As considerações finais, após as constatações observadas neste estudo em relação ao seu objetivo proposto, se resumem a registrar a necessidade de implementações de equipamentos que possam facilitar o trabalho descarregamento do açaí no Mercado o Ver-o-Peso pelos carregadores. Mas, por outro lado, devemos considerar também a visão moderna de ergonomia, proposta por alguns autores mencionados neste artigo, os quais não restringem o assunto à relação homem/máquina, mas o estendem para o ambiente $\mathrm{e}$ condições de trabalho em geral onde o equipamento se instala. 


\section{Referências}

ALENCAR FILHO, J. G. Ergonomia. Recife: FESP/UPE, (Apostila Curso de Especialização em Engenharia de Segurança do Trabalho), 1993. CAMACHO, J. S. Psicologia organizacional: Uma abordagem sistêmica. São Paulo: EPU, 1984.

CANTO, S. A. E. Processo extrativista do açaí contribuição da ergonomia com base na análise postural durante a coleta dos frutos. 2001. 115f. Dissertação (Mestrado em Engenharia de Produção) - Universidade Federal de Santa Catarina, Florianópolis, 2001.

DUL, J.; WEERDMEESTER, B. Ergonomia prática. Tradução de Itiro lida, da versão inglesa Ergonomics for Beginners, 1993. São Paulo: Edgard Blücher Ltda, 1995.

EGGERS, C.; GOEBEL, M. A. Princípios de higiene e segurança no trabalho. Revista Perspectiva, Florianópolis, v. 6, n. 6, p. 103-117, 2007.

GRANDJEAN, E. Manual de ergonomia: adaptando o trabalho ao homem. Porto Alegre: Artes Médicas, 1998.

HOMMA, A. K. O.; NOGUEIRA, O. L.; MENEZES, A. J. E. A.; CARVALHO, J. E. U.; NICOLE, C. M. L.; MATOS, G. B.; Açaí: novos desafios e tendências. Amazônia, Belém, v. 2, p. 7-23, 2006.

IIDA, I. Ergonomia projeto e produção. São Paulo: Edgard Blücher Ltda, 1993.

INPS Análises profissiográficas. Indústria têxtil. Rio de Janeiro: Instituto Nacional de Previdência Social - Secretaria de Seguros Sociais, 1969.

LEPLAT, J. La psychologie ergonomique. Coll. Que Sais-Je? Paris: Presses Universitaires de France, 1980.

MINISTÉRIO DO TRABALHO. Anuário Estatístico de Acidentes do Trabalho 2008.2 Disponível em: <http://www. previdenciasocial.gov.br/conteudoDinamico>. Acesso em: 16 dez. 2010.

MONTMOLLIN, M. L'analyse du travail, l'ergonomie, la "qualité de la vie de travail les americains, et nous. Le Travail Humain. Paris, tome 45, 1971.

MURREL, K. F. H. Ergonomics: Man in his working environment. London: Chapman and Hall, 1965.

PINHEIRO, F. A.; TRÓCCOLI B. T.; CARVALHO, C. C. Validação do Questionário Nórdico de Sintomas Osteomusculares como medida de morbidade. Revista de Saúde Pública, São Paulo, v. 36, n. 3, p. 307-312, 2002.

RODRIGUES, L. B.; SILVA, A. G.; VELOSO, C. M.; ALMEIDA, A. S. O. Programa de Prevenção de Acidentes de Trabalho. In: I CBEU - 
Congresso Brasileiro de Extensão Universitária, 2002, João Pessoa. I CBEU - Congresso Brasileiro de Extensão Universitária, v. Único. p. 1-4, 2002.

ROTHMANN, I.; COOPER, C. Fundamentos de psicologia organizacional e do trabalho, tradução de Luiz Claudio de Queiroz. Rio de Janeiro: Elsevier, 2008.

SANTANA, N. B.; SANTOS, C. X.; RODRIGUES, L. B. (2004). Levantamento dos riscos ocupacionais presentes em uma indústria de sorvetes. XI SI MPEP. Bauru, SP, 2004.

SANTOS, N.; FIALHO, F. A. P. Manual de análise ergonômica do trabalho. Curitiba: Gênesis, 1997.

WIKIPEDIA. Ver-o-peso. Wikipedia. Disponível em <http://pt. wikipedia.org/wiki/Ver-o-Peso>. Acesso em: 01 dez. 2010. WISNER, A. Por dentro do trabalho: Ergonomia, método e técnica. São Paulo: FTD/Oboré, 1987.

Agradecimentos ao Prof. Me. Laércio de Sousa Silva, do IESAM, como consultor, e às alunas Larissa Emmanuelle R. D. Quaresma, Thayná do Nascimento Chagas e Lorena Mayara Tenório Santana, da UFPA, como colaboradores na coleta de dados. Ao Alan Oliveira de Assis Rocha, video maker, pela gravação e edição de vídeo sobre as atividades dos carregadores.

\section{Endereço para correspondência}

J oão Bosco de Assis Rocha

Universidade Federal do Pará - Faculdade de Psicologia

Rua Augusto Correa, 01, Guamá, Caixa Postal, 479, CEP 66075-110-Belém-PA.

Endereço eletrônico: bosco@ufpa.br

\section{Edmundo Rinolino Magalhães Flores}

Universidade Federal do Pará - Faculdade de Psicologia

Rua Augusto Correa, 01, Guamá, Caixa Postal, 479, CEP 66075-110-Belém-PA.

Endereço eletrônico: edmagalhaesf@gmail.com

Leandro Cavalcante Lima

Universidade Federal do Pará - Faculdade de Psicologia

Rua Augusto Correa, 01, Guamá, Caixa Postal, 479, CEP 66075-110-Belém-PA.

Endereço eletrônico: leandrocavalcantelima@gmail.com

\section{Leandro de J esus Rodrigues}

Universidade Federal do Pará - Faculdade de Psicologia

Rua Augusto Correa, 01, Guamá, Caixa Postal, 479, CEP 66075-110-Belém-PA.

Endereço eletrônico: leandrorodrigues83@msn.com

Recebido em: 17/01/2011

Reformulado em: 21/06/2011

Aceito para publicação em: 27/06/2011

Acompanhamento do processo editorial: Deise Mancebo

\section{Notas}

* Professor Doutor.

**Acadêmico de Psicologia. 